\title{
PENGARUH SISTEM PERJANJIAN KERJA WAKTU TERTENTU DAN MOTIVASI KERJA TERHADAP KINERJA KARYAWAN PADA INDUSTRI PABRIK GULA
}

\author{
Dwi Junianto ${ }^{1)}$, Joko Sabtohadi' ${ }^{2}$ \\ 1) Mahasiswa Program Magister Manajemen STIE Perbanas \\ ${ }^{2)}$ Balitbangda Kabupaten Kutai Kertenagara \\ Email: 1)junianto97@gmail.com, ${ }^{2)}$ sabtohadijoko@yahoo.co.id
}

\begin{abstract}
Abstrak
Tujuan dari penelitian adalah untuk menyelidiki pengaruh sistem kontrak PKWT, motivasi terhadap kinerja karyawan di Pabrik Gula Modjopanggoong Tulungagung. Populasi dalam penelitian adalah karywan PKWT atau pegawai tidak tetap bagian Instalasi yang berjumlah 112 orang. Teknik pengumpulan data dengan menggunakan media kuisioner dan teknik sampel sensus. Teknik analisis data memakai menggunakan Structural Equation Modelling-Partial Least Square (SEM-PLS) dengan software SmartPLS 2.0 Berdasarkan hasil penelitian ditemukan bahwa variabel sistem kontrak PKWT dan motivasi berpengaruh positif dan signifikan terhadap kinerja karyawan.
\end{abstract}

Kata Kunci: PWKT, Motivasi, Kinerja Karyawan

\begin{abstract}
This study is aimed at investigating the effect of PKWT contract system and motivation on employee performance at Modjopanggong Sugar Plant Tulungagung. The population of the study were all of 112 contract employee's technical department. Data collection techniques were carried out using questionnaire and census sampling technique methods. This study using structural equation modeling-partial least square with help of SmartPLS 2.0 software. The results of the study indicated the PKWT contract system and motivation positive significant influence employee performance.
\end{abstract}

Keywords: PWKT, Motivation, Employees' Perfomance

\section{PENDAHULUAN}

Industri gula yang ada di Indonesia telah ada sejak jaman pemerintahan Kolonial Belanda. Gula merupakan salah satu komuditas yang strategies sehingga pemerintahan Indonesia menasionalisasi industri gula. Eksistensi industri gula saat ini dihadapkan berbagai permasalahan yang kompleks.

Permasalahan utama dalam sistem pergulaan nasional yaitu belum terpenuhinya kebutuhan konsumsi gula nasional. Penurunan produksi tersebut disebabkan berbagai faktor, baik dari sisi teknologi, ekonomi dan sosial budaya. Secara teknis penurunan produktifitas ditinjau dari dua sisi yaitu menurunnya tingkat produktifitas tebu (ton/ha) dan efisiensi pabrik yang rendah.

Kinerja pabrik yang handal merupakan jaminan selama proses produksi yang berkisar antara $5-8$ bulan, setelah itu pabrik akan menjalani masa perbaikan peralatan (over houl). Indikatornya adalah rendahnya jam berhenti pabrik dikarenakan adanya kerusakan peralatan. Kehandalan pabrik adalah kunci utama, baik pada masa luar masa giling (LMG) dan dalam masa giling (DMG). Strategi program kerja harus dapat mengatasi dan mengantisipasi berbagai kendala yang akan menyebabkan down time.

Tak dapat dipungkuri bahwa SDM merupakan elemen penting yang harus diberikan sentuhan baik secara manajerial maupun teknis. Di pabrik gula terdapat karyawan dengan status perjanjian kerja waktu tertentu (PKWT) yang bekerja saat pabrik mulai operasional sampai berakhirnya giling. Pada status pekerja dalam perjanjian kerja di Pabrik Gula Rejo Agung terdapat terdapat dua jenisyaitu PKWTT dan PKWT, dimana masing- 
masing bagian tersebut telah terdapat hak, tugas dan kewajiban sesuai yang tertuang dalam perjanjian kerja (Winarsih, et al., 2019).

Menurut Davis (2000:67) bahwa pencapaian kinerja dipengaruhi oleh faktor kemampuan dan faktor motivasi. Kinerja karyawan merupakan output yang dicapai baik secara kuantitas maupun kualitas. Setiap karyawan dalam melaksanakan tugasnya sesuai dengan job description yang melekat sebagai tanggung jawabnya. Tujuan organisasi dapat dicapai dengan kinerja karyawan semakin meningkat melalui prestasi yang ditunjukkan ditempat kerja (Anwar et al., 2015).

Menurut Dharma (2004:349), tujuan penilain kinerja dalam rangka peningkatan produktifitas secara kualitas, kuantitas dan ketepatan waktu. Evaluasi penilaian kinerja karyawan dilakukan secara objektif sesuai dengan pencapaian dari setiap karyawan.

Peningkatan kinerja karyawan akan membawa dampak positif bagi perusahaan. Pemberdayaan kualitas SDM dilakukan dengan berbagai metode pelatihan baik insitu dan ex-situ. Maksudnya adalah karyawan mampu bekerja secara smart dan berkemampuan problem solver yang baik. Selain itu pula adanya sentuhan dari pimpinan yang berupa penciptaan suasana kerja bernuasa kondusif, pemberian reward terhadap prestasi kerja dan terjalinya komunikasi yang baik (Anwar et al., 2019).

Motivasi dan kontrak kerja PKWT yang dilaksanakan oleh perusahaan dewasa ini adalah hal yang penting dalam mencapai sasaran kinerja. Penelitian Retnosari dan Haryono (2016), penerapan secara baik pada pekerja kontrak mampu memberikan kontribusi dalam peningkatan kinerja karyawan. Sedangkan penelitian Larasati dan Gilang (2014), membuktikan bahwa motivasi berpengaruh positif dan signifikan terhadap kinerja karyawan.
Menurut Mangkunegara (2010), bahwa terdapat beberapa aspek dalam pengukuran kinerja karyawan yaitu : hasil pekerjaan, kreatifitas, kecapakan, tanggungjawab, mutu pekerjaan, inisiatif, kehadiran, sikap, ketepatan waktu penyelesaian pekerjaan, ketepatan kerja dan kualitas kerja.

Pabrik Gula dewasa ini juga menerapkan sistem kontrak kerja PKWT dalam merekrut karyawan. Karyawan PKWT disebut juga sebagai karyawan tidak tetap yang bekerja sesuai kesepakatan antara pemberi kerja dan pekerja itu sendiri. UU RI No. 13 tahun 2003, "pekerja/buruh merupakan setiap orang yang bekerja dengan menerima upah atau imbalan dalam bentuk lain". Sedangkan, pemberi kerja adalah "perseorangan, pengusaha, badan hukum atau badan-badan lainnya lainnya yang mempekerjakan tenaga kerja dengan membayar upah atau imbalan dalam bentuk lain".

Berdasarkan UU RI No. 13 Tahun 2003 pasal 59 ayat 4 ketentuan mengenai PKWT diadakan paling lama 2 tahun dan hanya dapat diperpanjang 1 kali dalam durasi waktu paling lama 1 tahun. Dalam UU tersebut terdapat indikator pengukurannya yaitu jenis pekerjaan, besarnya upah dan pembayaran, hak dan kewajiban, durasi kerja.

Motivasi merupakan salah satu faktor yang berpengaruh terhadap kinerja karyawan. Motivasi akan memberikan energy seseorang untuk melakukan tindakan dalam meraih tujuan. Sumber motivasi didapatkan baik secara intrinsik dan ekstrinsik.

Integrasi antara valensi, harapan dan instrumen adalah konsep mengenai motivasi yang dikemukakan oleh Victor $\mathrm{H}$. Vroom. Mangkunegara (2005), menyatakan instrumen merupakan penghargaan yang diberikan kepada seseorang. Pengukuran motivasi karyawan dilakukan melalui indikator yaitu perilaku karyawan dalam bekerja, etos kerja, 
tanggungjawab dan menikmati dalam bekerja.

Berdasarkan teori tersebut diatas, Gambar 1 merupakan merupakan kerangka pemikiran penelitian sebagai berikut:

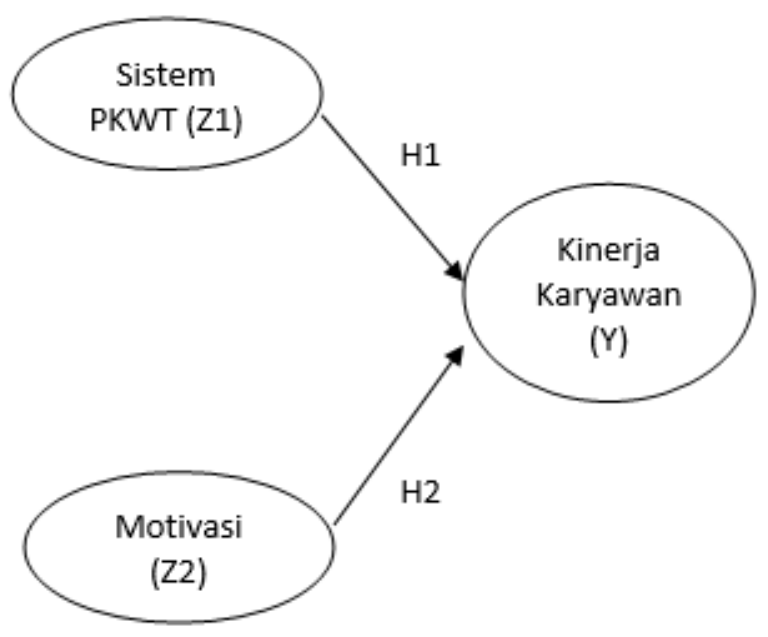

Gambar 1 : Kerangka Penelitian

Hipotesa penelitian ini adalah:

$$
\begin{aligned}
& \begin{array}{l}
\text { Sistem PKWT } \\
\text { berpengaruh positif } \begin{array}{r}
\text { dan } \\
\text { signifikan terhadap Kinerja } \\
\text { Karyawan (Y) }
\end{array} \\
\text { H2 : }
\end{array} \\
& \begin{array}{l}
\text { Motivasi (Z2) berpengaruh } \\
\text { positif dan signifikan terhadap } \\
\text { Kinerja Karyawan (Y) }
\end{array}
\end{aligned}
$$

\section{METODE PENELITIAN}

\section{Tempat dan Waktu Penelitian}

Pengumpulan data dilakukan selama periode waktu bulan Mei - September 2019 pada karyawan PKWT Pabrik Gula Modjopanggoong Tulungagung yang berkapasitas olah 2800 ton tebu per hari.

\section{Variabel Penelitian}

Penelitian ini terdapat 2 (dua) variabel eksogen yaitu sistem PKWT (Z1) dan motivasi (Z2). Sedangkan variabel endogennya adalah kinerja karyawan (Y).

Sistem PKWT merupakan bentuk kesepakatan kontrak kerja antara pemberi kerja dan karyawan selama durasi waktu tertentu yang memuat hak dan kewajiban. Adapun indikator berupa:

a. Perjanjian kontrak kerja (Z1.1)

b. Durasi kerja (Z1.2)

c. Hak dan kewajiban (Z1.3)

d. Sistem pengupahan (Z1.4).

Motivasi kerja adalah energi yang dimiliki oleh karyawan dalam melaksankan tugas secara baik. Indikator motivasi kerja yang digunakan dalam penelitian ini adalah:

a. Kesesuaian pekerjaan (Z2.1)

b. Etos kerja (Z2.2)

c. Team work (Z2.3)

d. Tanggungjawab (Z2.4)

Kinerja karyawan merupakan output yang dihasilkan sesuai tugas dan tanggungjawab yang dibebankan perusahaan kepada karyawan. Indikatornya adalah:

a. Tepat waktu (Y1.1)

b. Inisiatif (Y1.2)

c. Ketaatanakan standard operation procedure (Y1.3)

d. Target kerja (Y1.4)

\section{Jenis dan Sumber Data}

Penelitian ini menggunakan data primer yang langsung diperoleh dari responden penelitian. Kuesioner merupakan alat pengumpulan data.

\section{Populasi}

Adapun populasi dalam penelitian ini adalah karyawan tidak tetap dengan status PKWT. PKWT tersebut bekerja selama proses giling tebu sampai dengan akhir giling. Karyawan yang berstatus PKWT tersebut dipekerjakan sebagai tenaga operator, tenaga mekanik yang bertugas untuk melakukan perbaikan. Selain itu pula terdapat tenaga welder, machining.

\section{Sampel}

Menurut Malhotra (2015), sampel merupakan bagian dari populasi yang diambil dengan karakteristik tertentu. Penelitian ini menggunakan sampel jenuh yaitu seluruh karyawan PKWT bagian instalasi yang berjumlah 112 responden. 


\section{Teknik Pengumpulan Data}

Teknik pengupulan data dengan menggunakan kuesioner yang berupa pernyataan untuk ditanggapi oleh responden.

\section{Skala Pengukuran Data}

Menggunakan skala likert, yang memiliki dua pernyataan positif dan negative dengan skala 5. Skala 5 merupakan pernyataan sangatsetuju, sedangkan 1 pernyataan sangat tidak setuju.

\section{Teknik Analisis Data}

Adapun teknik analisis data dalam penelitian ini menggunakan Structural Equation Modeling - Partial Least Square (SEM-PLS). Pendapat Solimun (2015), bahwa analisis SEM-PLS terdiri dari:

a. Merancang model struktural.

b. Merancang model pengukuran.

c. Mengkonstruksi diagram jalur.

d. Konversi diagram jalur ke persamaan.

e. Melakukan estimasi.

f. Evaluasi goodness of fit dan pengujian hipotesis.

Teknik analisis data menggunakan software SmartPLS versi 2.0. SmartPLS mempunyai banyak keunggulan dalam olah data dalam bentuk SEM. Partial Least Squares (PLS) salah satu metode statistika SEM berbasis varian yang bertujuan untuk dalam menyelesaikan regresi berganda jika terjadi permasalahan spesifik data, seperti ukuran sampel yang kecil adanya data yang hilang dan multikolinieritas (Hamid \& Anwar, 2019).

\section{HASIL DAN PEMBAHASAN}

\section{Pengujian Model Pengukuran}

Outer model bertujuan mengetahui validitas dan realibilitas dari masingmasing indikator terhadap variabel latennya. Uji validates konvergen, uji validitas diskriminan, dan uji reliabilitas ini dilakukan untuk pengujian model pengukuran.

\section{Uji Validitas Konvergen}

Uji validitas konvergen bertujuan untuk menguji besarnya korelasi antara indicator dengan variabel laten. Uji validitas konvergen dalam PLS reflektif dinilai berdasarkan loading factor. Nilai loading factor disajikan dalam Gambar 2 sebagai berikut:

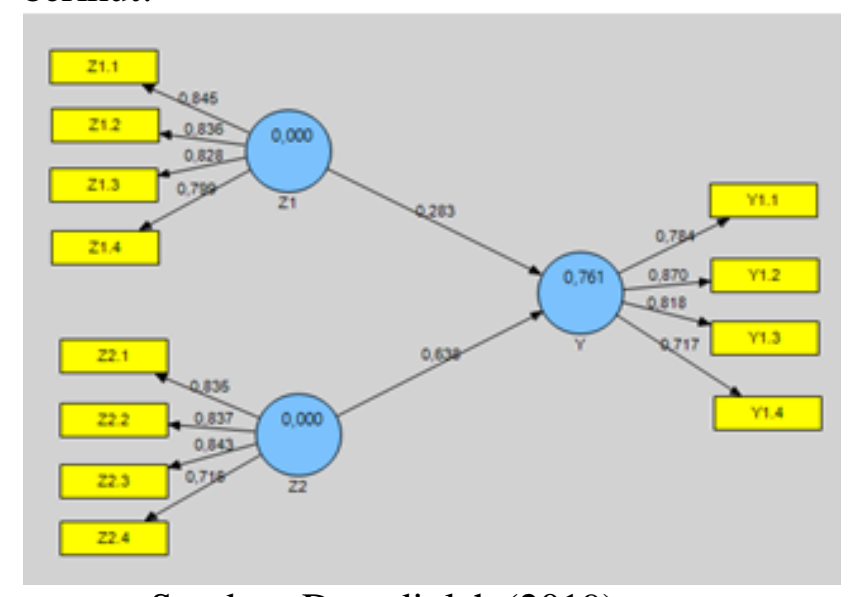

Sumber: Data diolah (2019)

\section{Gambar 2: Hasil uji loading factor}

Nilai AVE disajikan pada Tabel 1 sebagai berikut:

Tabel 1

Nilai AVE

\begin{tabular}{ll}
\hline Variabel & AVE \\
\hline $\mathrm{Z1}$ & 0,683 \\
$\mathrm{Z} 2$ & 0,654 \\
$\mathrm{Y}$ & 0,638 \\
\hline
\end{tabular}

Sumber: data diolah (2019)

Role of thumbs yang digunakan dalam validitas konvergen adalah outer loading > 0,7 dan Average Variance Extracted (AVE) > 0,5 (Chin, 1995). Berdasarkan Gambar 2 dan Tabel 1 didapatkan hasil bahwa validitas konvergen menunjukkan semua indicator mampu menjelaskan masing-masing variabel latennya. Hal tersebut dinyatakan dengan nilai outer loading > 0,7 dan nilai AVE > 0,5. Dengan demikian dapat dikatakan valid.

\section{Uji Validitas Diskriminan}

Pengujian validitas diskriminan bertujuan untuk mengetahui prinsip pengukur- 
pengukuran konstruk yang berbeda seharusnya tidak berkorelasi tinggi. Uji pengukuran validitas diskriminan dinilai dengan melihat cross loading pengukuran dengan konstruknya.

Setiap indikator akan dikatakan mampu menjelaskan variabelnya di bandingkan variabel lainnya jika nilai cross loading antar indikator dengan variabel latennya > dari nilai cross loading antara indikator dengan laten lainnya (Fornell dan Locker, 1981 dalam Ghozali dan Latan, 2014). Nilai cross loading disajikan pada Tabel.

Tabel 2

Nilai Cross loading indikator

\begin{tabular}{llll}
\hline & Z1 & Z2 & Y \\
\hline Z1.1 & $\mathbf{0 , 8 4 5}$ & 0,749 & 0,759 \\
Z1.2 & $\mathbf{0 , 8 3 6}$ & 0,541 & 0,528 \\
Z1.3 & $\mathbf{0 , 8 2 8}$ & 0,574 & 0,589 \\
Z1.4 & $\mathbf{0 , 7 9 9}$ & 0,611 & 0,620 \\
Z2.1 & 0,604 & $\mathbf{0 , 8 3 5}$ & 0,654 \\
Z2.2 & 0,596 & $\mathbf{0 , 8 3 7}$ & 0,635 \\
Z2.3 & 0,666 & $\mathbf{0 , 8 4 3}$ & 0,787 \\
Z2.4 & 0,584 & $\mathbf{0 , 7 1 6}$ & 0,662 \\
Y1.1 & 0,631 & 0,653 & $\mathbf{0 , 7 8 4}$ \\
Y1.2 & 0,620 & 0,720 & $\mathbf{0 , 8 7 0}$ \\
Y1.3 & 0,620 & 0,720 & $\mathbf{0 , 8 7 0}$ \\
Y1.4 & 0,620 & 0,720 & $\mathbf{0 , 8 7 0}$ \\
\hline
\end{tabular}

Sumber: data diolah (2019)

Pada Tabel 2 didapatkan masing-masing indikator memiliki nilai cross loading yang lebih besar dengan variabel latennya disbanding dengan variabel lainnya. Sehingga, dapat disimpulkan indikatorindikator yang digunakan dalam penelitian ini mampu menjelaskan variabel laten yang diteliti. Jadi kesimpulannya adalah telah memenuhi syarat validitas diskriminan.

Tabel 3

Akar AVE

\begin{tabular}{ccc}
\hline Aariabel & AVE Kuadrat \\
AVE & Keputusan \\
\hline
\end{tabular}

\begin{tabular}{cccc}
\hline Z1 & 0,683 & 0,826 & Diterima \\
Z2 & 0,654 & 0,808 & Diterima \\
Y & 0,638 & 0,798 & Diterima \\
\hline
\end{tabular}

Sumber: data diolah (2019)

Metode lain yang dipakai dalam menilai validitas diskriminan dengan membandingkan akar AVE. Syarat validitas diskriminan apabila jik aakar AVE setiap konstruk > dari pada korelasi antara konstruk dengan konstruk. Pada Tabel 3, dapat dijelaskan bahwa role of thumbs validitas diskriminan adalah valid.

\section{Uji Reliabilitas}

Uji reliabilitas dilakukan dengan tujuan mengukur konsistensi internal alat ukur. Dalam SEM-PLS uji reliabilitas dapat digunakan dua metode yaitu : cronbach's alpha dan composite reliability.

Cronbach's alpha merupakan pengukuran batas bawah dari nilai reliabilitas. Composite reliability akan mengukur nilai sesungguhnya reliabilitas suatu kontruk. Role of thumbs dari cronbach's alpha adalah lebih besar dari 0,6, dan composite reliability lebih besar dari 0,7. Penelitian ini bersifat eksploratif nilai cronbach's alpha dan composite reliability sebesar 0,6 - 0,7 masih dapat diterima(Ghozali dan Latan, 2014).

Hasil uji reliabilitas dilakukan dengan melihat nilai composite reliability tersaji pada Tabel 4.

Tabel 4

Nilai Composite Reliability

\begin{tabular}{ll}
\hline $\begin{array}{l}\text { Variabel } \\
\text { Laten }\end{array}$ & Composite Realibility \\
\hline PKWT (Z1) & 0,896 \\
Motivasi (Z2) & 0,883 \\
Kinerja (Y) & 0,876 \\
\hline \multicolumn{2}{l}{ Sumber: data diolah (2019) }
\end{tabular}

Selanjutnya dilihat juga dari nilai cronbach's alpha, tersaji pada Tabel 5. 
Tabel 5

Nilai cronbach's alpha

\begin{tabular}{ll}
\hline Variabel & Cronbach's alpha \\
\hline Z1 & 0,847 \\
Z2 & 0,822 \\
Y & 0,809 \\
\hline
\end{tabular}

Sumber: data diolah (2019)

Berdasarkan hasil uji data yang disajikan pada Tabel 4 dan Tabel 5 diketahui nilai composite reliability dan cronbach's alpha dari masing-masing variabel laten yang dianalisis memenuhi kiteria uji reliabilitas. Dengan demikian, dapat dikatakan bahwa instrumen yang digunakan mengukur variabel laten dalam penelitian ini adalah reliabel.

\section{Pengujian Model Struktural}

$R$-square digunakan untuk mengevaluasi kecocokan model dalam uji model struktural antar variabel laten. Menurut Chin dalam Ghozali dan laten (2014), bahwa role of thumbs dari kecocokan model apabila nilai $\mathrm{R}^{2}$ sebesar 0,67 memberikan arti model dikategorikan "baik"; nila $\mathrm{R}^{2}$ sebesar 0,3 memberikan arti model yang dibuat diklasifikasikan "moderat"; dan nilai $\mathrm{R}^{2}$ sebesar 0,19 akan memiliki makna bahwa model yang dibuat diklasifikasikan "lemah"

Berdasarkan hasil analisis yang diperoleh, nilai $\mathrm{R}^{2}$ sebesar 0,761 . Dengan demikian diartikan bahwa model yang dibuat mengindikasikan model yang baik.

\section{Pengujian Hipotesis}

Prosedur resampling bootstrap digunakan dalam pengujian hipotesis penelitian mempergunakan uji t-statistik. Apabila nilai t-satistik (t-hitung) dibandingkan dengan > t-tabel disimpulkan $\mathrm{H} 1$ diterima dan H0 ditolak. Nilai t-tabel yang digunakan dalam penelitian ini adalah 1,96 (two tailed test, dengan nilai alpha sebesar $0,05)$.

Hasil bootsrapping pada penelitian ini tersaji pada Gambar 3. Adapun nilai path coeficient dan t-statistik (t-hitung) pengaruh variabel sistem PKWT dan motivasi kerja terhadap kinerja karyawan dapat dilihat pada Tabel 6.

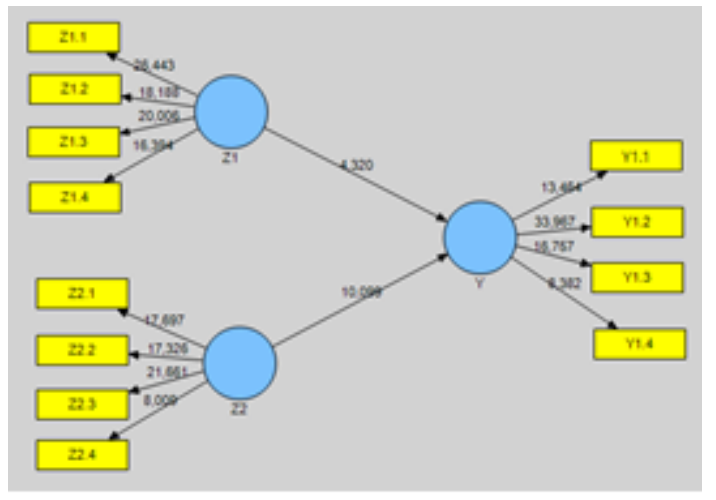

Sumber : data diolah (2019)

Gambar 3. Hasil Bootstrapping

Tabel 6

Nilai path coefficient dan T-statistik

\begin{tabular}{lcc} 
& Path Coeficient & T Statistic \\
\hline Z1 --> Y & 0,2820 & 4,320 \\
Z2 --> Y & 0,6370 & 10,099 \\
\hline
\end{tabular}

Sumber: data diolah (2019)

Pada Gambar 3 dan Tabel 6 menunjukkan hasil bahwa nilai t-hitung untuk path coefficient pengaruh $\mathrm{Z} 1$ terhadap $\mathrm{Y}$ sebesar 4,320 (lebih besar dari 1,96). Dari hasil tersebut disimpulkan bahwa sistem PKWT berpengaruh positif dan signifikan terhadap kinerja karyawan.

Selain itu, ditunjukan pula bahwanilai thitung untuk path coefficient pengaruh Z2 terhadap Y sebesar 10,099 (lebih besar dari 1,96). Dengan demikian, disimpulkan variabel motivasi berpengaruh positif dan signifikan terhadap kinerja karyawan.

Jika ditinjau pada nilai perbandingan pada path coefficient didapatkan bahwa path coeficient Z2 terhadap $\mathrm{Y}$ lebih besar dibandingkan Z1 terhadap Y. Kinerja karyawan pada Pabrik Gula Modjopanggoong variabel motivasi mempunyai pengaruh yang lebih besar dari variabel sistem PKWT. 


\section{Pengaruh sistem PKWT terhadap kinerja karyawan}

Hasil pengujian bahwa sistem PKWT terhadap kinerja karyawan memberikan hasil berpengaruh positif dan signifikan. Manajemen Pabrik Gula Modjopanggoong Tulungagung telah dapat menerapkan kontrak kerja yang berdasarkan sistem PKWT secara baik. Sistem kontak kerja merupakan subsarana yang memberikan kontribusi dalam kinerja karyawan (Suparno, 2015).

Mengingat bahwa operasional pabrik gula dalam musim giling yang berlangsung selama lima sampai delapan bulan sehingga kualitas kontrak kerja sistem PKWT merupakan bagian yang penting. Didalam kontrak yang dituangkan harus memuat hak dan kewajiban, durasi waktu, besarnya gaji atau upah. Dengan adanya kejelasan kontrak antara pemberi kerja dengan pekerja tentunya akan menciptakan quality of work life yang membuat karyawan merasa betah dan memberikan kinerja terbaiknya.

Menurut Dunggio dan Basri (2019), bahwa kejelasan kontrak kerja yang tertuang dalam perjanjian kerja karyawan akan memahami yang menjadi tanggungjawabnya dan perusahaan atau pemberi kerja. Terciptnya sinergi ini akan memiliki tujuan untuk tumbuh dan berkembangannya perusahaan dalam menciptakan profit. Kinerja pegawai merupakan perwujudan yang dilakukan oleh para pegawai untuk mencapai tujuan didalam sebuah organisasi sesuai dengan prosedur yang telah ditetapkan oleh organisasi (Abror, 2019).

\section{Pengaruh motivasi terhadap kinerja karyawan}

Hasil pengujian bahwa motivasi terhadap kinerja karyawan memberikan hasil berpengaruh positif dan signifikan di Pabrik Gula Modjopanggoong Tulunggagung. Dengan adanya peningkatan motivasi dalam pelaksanaan tugas akan memberikan kinerja karyawan yang semakin tinggi pula. Hal ini sesuai dengan penelitian yang dilakukan oleh (Ramlan, 2018).

Motivasi karyawan merupakan wujud quality of work life yang dirasakan dan adanya dukungan manajemen. Lingkungan organisasi dan pemenuhan sarana kerja akan menunjang produktifitas karyawan dalam penyelesaian tugas yang dibebankan perusahaan. Lingkungan kerja baikfisik dan non fisik akan menghasilkan kinerja yang lebih optimal (Abi et al., 2018). Lingkungan kerja akan memberikan kontribusi dalam peningkatan kinerja (Rohmah, 2019).

Kerja sama dalam tim atau team work sebagai salah satu upaya dalam peningkatkan kinerja karyawan. Sentuhan pemimpin sangat diperlukan dalam pembinaan dan menjaga irama kerja karyawan dalam organisasi. Hal didasarkan pada pencapaian target secara bersama karena sistem produksi dalam pabrik gula dilakukan secara kontinyu. Karyawan kontrak akan bekerja dalam shift bersama dengan karyawan tetap (pagi, siang dan malam).

Setiap karyawan PKWT telah dibagi dalam setiap shift dan dikendalikan oleh asisten manajer. Selain itu pula juga dibekali dengan keterampilan agar dapat melaksanakan tugas dan tanggung jawabnya dengan baik. Hal ini ditunjukkan dengan adanya inisiatif penyeleaian pekerjaan yang sesuai dengan system operation procedure.

Dalam operasional giling selalu dipedomani dengan keajegan kapasitas giling, pemenuhan kebutuhan utilitas proses, kecepatan dalam perbaikan peralatan merupakan tujuan dan target perusahaan. Adanya kekompakan tim dan semangat kerja merupakan manisfestasi hasrat karyawan sebagai upaya pencapaian kualitas pekerjaan. Kondisi tersebut selalu dapat tercipta dengan dorongan motivasi baik dalam diri karyawan dan dukungan manajemen. 


\section{SIMPULAN}

Hasil pembahasan yang dilakukan bahwa sistem kerja PKWT dan motivasi berpengaruh positif dan signifikan terhadap kinerja karyawan. Artinya bahwa pihak manajemen senantiasa memperhatikan faktor-faktor tersebut diatas guna kelangsungan hidup perusahaan agar terus tumbuh dan berkembang. Sistem kerja PKWT yang dituangkan dan disepakati oleh kedua belah pihak telah secara jelas memberikan informasi akan hak dan kewajiban.

Setiap perusahaan selalu membutuhan karyawan yang memiliki pengetahuan, keterampilan dan sikap dalam mendukung tugas dan tanggungjawabnya, selain itu pula untuk memberikan output produktifitas kerja sangat diperlukan adanya dukungan sarana kerja. Selain itu terciptnya motivasi kerja agar terjadi semangat yang sama dalam pencapaian target perusahaan. Motivasi ini baik secara individu maupun kerja tim yang miliki inisiatif dan selalu tanggap akan pekerjaan sesuai system operation procedure yang berlaku.

\section{DAFTAR PUSTAKA}

Abi, W.O., Ridjal, S., \& Alam, S. (2018). Pengaruh kepemimpinan, kompetensi dan lingkungan kerja terhadap kinerja pegawai (studi kasus Dinas Kehutanan Provinsi Sulawesi Selatan). Bongaya Journal for Research in Management, 1(1), 14-28.

Abror, M. (2019). Pengaruh Pengembangan Karir, Motivasi Dan Kompetensi Terhadap Kinerja Pegawai Puskesmas Rambah Samo II. HIRARKI: Jurnal Ilmiah Manajemen Dan Bisnis, 1(2), 1823.

Anwar, S. M., \& Darmawati, D. (2019). Pengaruh Motivasi Dan Komitmen Terhadap Karyawan PT. Mutiara
Di Kecamatan Mappedeceng. Equilibrium: Jurnal Ilmiah Ekonomi, Manajemen dan Akuntansi, 7(1), 25-33.

Anwar, S. M., \& Ecce, E. (2015). FaktorFaktor Yang Berpengaruh Terhadap Kinerja Karyawan Pada PT. Panply Kabupaten Luwu. Equilibrium: Jurnal Ilmiah Ekonomi, Manajemen dan Akuntansi, 5(1), 51-58.

Dunggio, M, \& Basri, S. (2019). Pengaruh sistem kerja kontrak dan motivasi kerja terhadap kinerja karyawan pada perusahaan erha clinic. Kinerja, 16(2), 166-174.

Ghozali, I., \& Latan, H. (2014). Partial Least Squares Konsep, Teknik dan Aplikasi Menggunakan Program SmartPLS 3.0 Untuk Penelitian Empiris (Edisi 2). Semarang: Badan Penerbit Universitas Diponegoro.

Hamid, R. S., \& Anwar, S. M. (2019). STRUCTURAL EQUATION MODELING (SEM) BERBASIS VARIAN Konsep Dasar dan Aplikasi Program Smart PLS 3.2.8 dalam Riset Bisnis. Jakarta: PT. Inkubator Penulis Indonesia.

Larasati, S., \& Gilang, A. (2014). Pengaruh Motivasi Kerja Terhadap Kinerja Karyawan Wilayah Telkom Jabar Barat Utara (Witel Bekasi). Jurnal Manajemen Dan Organisasi, V (3), 1-14.

Malhotra. (2015). Riset Pemasaran (Edisi 4). Jakarta: PT. Indeks.

Mangkunegara, A.A.A.P. (2010). Evaluasi Kinerja SDM. Jakarta: Refika Aditama.

Ramlan. (2018). Pengaruh Karir, Lingkungan Kerja, Motivasi, Dan 
Kepemimpinan Terhadap Kinerja Pegawai Di Pusat Informasi Pengawasan Badan Pengawasan Keuangan Dan Pembangunan. JIMFE: Jurnal Ilmiah Manajemen Fakultas Ekonomi, 4(2), 145-162.

Retnosari, I, Budi, L, \& Haryono, A.T. (2016). Pengaruh sistem kerja kontrak, kompensasi dan career path terhadap corporate performance dengan kinerja karyawan sebagai variabel intervening. Journal of Management, 2(2), 1-12.

Rohmah. R. A. (2019). Pengaruh Kemampuan, Motivasi Dan Kompensasi Terhadap Kinerja Pegawai Sekretariat Daerah Kabupaten Rokan Hulu. HIRARKI: Jurnal Ilmiah Manajemen Dan Bisnis, 1(2), 57-60.

Solimun. (2015). Model Pengukuran dan Overview Analisis PLS. Workshop Metode Kuantitatif SEM-PLS. Universitas Udayana Denpasar 27 -28 November.

Suparno, E. W. (2015). Manajemen Pengembangan Sumber Daya Manusia. Yogyakarta.

Winarsih., Sidanti, H., \& Purwanto, H. (2019). Pengaruh Status Pekerja PKWT Terhadap Kinerja Karyawan dengan Kepuasan Kerja sebagai variabel Intervening pada PG Rejo Agung di kota Madiun. In SIMBA: Seminar Inovasi Manajemen, Bisnis, dan Akuntansi, 1, 1014-1038. 